\title{
Description of a New Talitrid Genus, Ezotinorchestia with a Redescription of $E$. solifuga (Iwasa, 1939) comb. nov. (Crustacea: Amphipoda: Talitridae)
}

\author{
Hiroshi Morino ${ }^{1,3}$ and Hisashi Miyamoto ${ }^{2}$ \\ ${ }^{1}$ Department of Zoology, National Museum of Nature and Science, 4-1-1 Amakubo, Tsukuba, Ibaraki 305-0005, Japan \\ E-mail:morino631@gmail.com \\ 2 4-9 Kasumi, Maruoka-cho, Fukui 910-0231, Japan \\ E-mail: dream_50000000690737@yahoo.co.jp \\ ${ }^{3}$ Corresponding author
}

(Received 19 February 2016; accepted 13 May 2016)

http://zoobank.org/4FE2AA1E-C38B-4919-82C2-FEAD415FDEA9

\begin{abstract}
Ezotinorchestia gen. nov. is established to receive Orchestia solifuga Iwasa, 1939. The new genus is defined by an elongate antenna 1 (reaching the mid-point of peduncular article 5 of antenna 2), a 4-dentate lacinia of the left mandible, a mediodistally lobate article 2 and reduced article 4 of the maxillipedal palp, a deeply subchelate male gnathopod 1, the short palm of female gnathopod 1, cuspidactylate pereopods, well-developed pleopods, and the outer ramus of uropod 1 with robust setae. This genus is distinguished from Kokuborchestia Morino and Miyamoto, 2015 by the sexually dimorphic gnathopod 1 and the lack of dense, plumose setae on the pleopodal peduncles.
\end{abstract}

Key Words: Crustacea, Amphipoda, Talitridae, Ezotinorchestia, new genus, Ezotinorchestia solifuga, Hokkaido, Japan.

\section{Introduction}

Orchestia solifuga Iwasa, 1939 was described from terrestrial coastal habitats (damp places under fallen leaves on a small hill) near the Akkeshi Marine Biological Station in Hokkaido, Japan (Iwasa 1939). Bulycheva (1957) mistakenly synonymized this species with Orchestia traskiana Stimpson, 1857. In his revision of the North Pacific talitrids, Bousfield (1982) narrowed the concept of the genus Orchestia and restricted the constituent species to the Eastern Atlantic and Mediterranean. At the same time he established Traskorchestia Bousfield, 1982 to receive O. traskiana, but reserved judgement on the placement of $O$. solifuga due to its incomplete description. Recently, Sidorov and Barabanschikov (2010) redescribed O. solifuga based on a female specimen recovered from "subsurface" water in an estuary in northern Primorye, Russia; the Russian specimen, however, shows some morphological differences from Japanese specimens (see the "Remarks" section). Since the type has not been located so far (and is probably lost; H. Morino unpublished data), in this study we examined additional material from the nearest practical place to the type locality in Hokkaido to confirm its generic affiliation, and as a result we allocate $O$. solifuga to a new genus, as Ezotinorchestia solifuga (Iwasa, 1939) comb. nov.

\section{Materials and Methods}

Specimens were collected from terrestrial habitats near seacoasts in On-neto, Rausu, and Utoro, eastern Hokkaido; several specimens secured from the forests of Rishiri and Rebun Islands in northern Hokkaido were forwarded by Dr K. Ishii, which were also examined. The general methodology follows Morino (2014). The specimens were dissected under a stereomicroscope and appendages and bodies were illustrated under a light microscope using a drawing tube. The illustrated appendages were fixed on slide mounts with Hoyer's medium or kept in tubes with the bodies. The body length was measured from the tip of head to the tip of telson along the straightened dorsal margin. The specimens studied are lodged in the collection of the National Museum of Nature and Science, Tsukuba (NSMT) or in the private collection of H. Miyamoto.

Genus Ezotinorchestia gen. nov.

[New Japanese name: Kita-okatobimushi zoku]

Type species. Orchestia solifuga Iwasa, 1939.

Diagnosis. Body size medium. Eyes medium. Antenna 1 elongate, reaching mid-point of peduncular article 5 of antenna 2, peduncle subequal to flagellum in length, peduncular article 3 longer than either article 1 or 2 . Antenna 2 in male not incrassate, flagellum subequal to peduncle in length. Upper lip lacking robust setae. Lacinia of left mandible 4-dentate. In maxilliped, outer margin of precoxa not 
stepped, palp articles 2 and 3 broad and mediodistally lobate, article 4 reduced.

Gnathopod 1 sexually dimorphic, male propodus deeply subchelate, carpus and propodus each with broad-based pellucid lobe, merus with small pellucid lobe, lateral surface of propodus with rows of submarginal and facial robust setae; in female, pellucid lobe or scabrous surface both absent, propodus palm vertical, shorter than dactylus. In gnathopod 2 of male, propodus powerfully subchelate, dactylus slightly attenuate; in female, mitten-shaped, basis weakly expanded anteroproximally, propodus with facial and submarginal setae on lateral surface. Pereopods cuspidactylate (bi-cuspate), locking robust setae of propodi reduced. Coxa of pereopod 4 as deep as wide. Posterior lobe of coxa of pereopod 6 smoothly curved. Pereopod 7 in male not sexually dimorphic. Coxal gills of pereopods 2 and 6 larger than those of pereopods 3-5, gill of pereopod 2 lobed, others convoluted, gill of pereopod 6 distally linguiform.

Pleonite side plates lacking marginal pits; pleopodal peduncles with 2 retinacula, arrays of robust setae both marginally and facially, and well-developed rami. Uropod 1 with distolateral robust seta of peduncle shorter than subdistal one; inner ramus with outer and dorsal marginal robust setae, outer ramus with marginal robust setae. Uropod 2 with rami subequal in length and marginal robust setae in 1 or 2 rows. Uropod 3 with peduncle slightly expanded; ramus stout, shorter than peduncle. Telson wider than long, with dorsolateral, distolateral, and distal robust setae, 6-12 setae in total per lobe.

Oostegites subovate, with numerous simple or slightly curve-tipped setae.

Etymology. The generic name is a combination of the ancient name for the region of Hokkaido, Ezoti, and part of the generic name Orchestia.

Remarks. There are three genera of terrestrial coastal talitrids in the northwest Pacific: Ezotinorchesita gen. nov., Kokuborchestia Morino and Miyamoto, 2015, and Ditmorchestia Morino and Miyamoto, 2015. They show several morphological similarities among themselves. Ezotinorchestia is close to Kokuborchestia in having 1) an elongate antenna 1,2 ) a deeply subchelate and lobed merus-carpus in male gnathopod 1,3) well-developed pleopods, 4) outer ramus of uropod 1 with robust setae marginally, 5) laterally to distally distributed robust setae on the telson, and 6) simple-tipped setae on the oostegites. However, Kokuborchestia displays: 1) a similar gnathopod 1 in both sexes, with a deep palm and lobed merus-carpus (vs. sexually dimorphic), 2) the coxal gill of pereopod 6 being broad and distally truncate ( $v s$. distally linguiform), 3) densely setose (with plumose setae) peduncles of the pleopods ( $v s$. with robust setae), and 4) the telson lobe with 5-6 robust setae (vs. 6-12). These are all regarded as generic difference. Ditmorchestia displays similarities to Ezotinorchestia in having: 1) a sexually dimorphic gnathopod 1,2) a setose outer ramus of uropod 1 (with robust setae), and 3) a setose telson lobe (also with robust setae). However, the shorter antenna 1, the produced

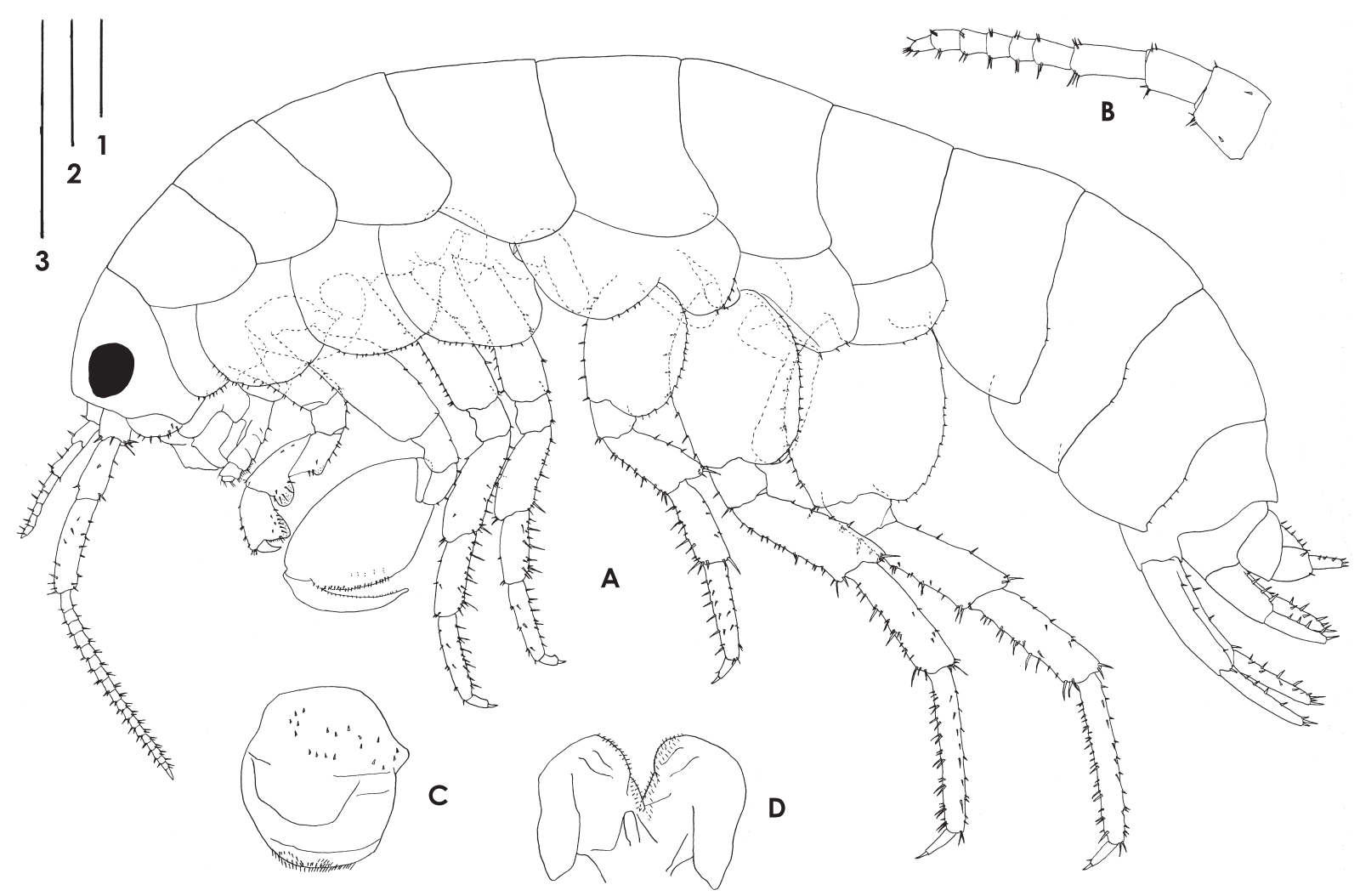

Fig. 1. Ezotinorchestia solifuga (Iwasa, 1939). Male, $12.9 \mathrm{~mm}$ (NSMT-Cr 24220), Utoro, Abashiri, Hokkaido, Japan. A, habitus, lateral view (after Morino 2015); B, antenna 1; C, upper lip; D, lower lip. Scale 1, $1.0 \mathrm{~mm}$ for A; scale 2, $0.2 \mathrm{~mm}$ for C and D; scale 3, $1.0 \mathrm{~mm}$ for B. 
basis of pereopod 7, the moderately reduced pleopods, and the robust ramus of uropod 3 in Ditmorchestia separate this genus from Ezotinorchestia.

Males of Orchestia Leach, 1814, as redefined by Lowry and Fanini (2013), and Cryptorchestia Lowry and Fanini, 2013, distributed mostly in the North Atlantic, show similar features to the present new genus in having: 1) a deeply subchelate gnathopod 1,2) well developed pleopods, and 3 ) robust setae on the outer ramus of uropod 1. In addition, the lobed merus of gnathopod 1 is shared by Cryptorchestia and the present genus, while a high number of robust setae on telson $(7+)$ is common to Orchestia and the present genus. However, both Orchestia and Cryptorchestia are separable from Ezotinorchestia by the shorter antenna 1, which does not exceed the end of peduncular article 4 of antenna 2. It should also be noted that recent molecular analyses of Orchestia and related species from the Mediterranean and northeast Atlantic suggest polyphyly of the genus Orchestia (Pavesi et al. 2015). Future molecular studies with extended species sampling could lead to further revision of the diagnosis of Orchestia.
Ezotinorchestia solifuga (Iwasa, 1939) comb. nov. [Japanese name: Kita-okatobimushi]

(Figs 1-3)

Orchestia solifuga Iwasa, 1939: 271-273, fig. 12, pl. 14; ? Sidorov and Barabanschikov 2010: 71-73, figs 1-5.

Non Orchesita traskiana Stimpson, 1857: Bulycheva 1957: 166, fig. 60.

“Parorchestia” solifuga (Iwasa, 1939): Bousfield 1984: 207.

Non Platorchestia solifuga (Iwasa, 1939): Miyamoto 1984: 3.

"Orchestia" solifuga Iwasa, 1939: Morino et al. 2009: 26; Morino 2015: 1076 (fig. 1), 1087.

Material examined. Male $12.9 \mathrm{~mm}$ (NSMT-Cr 24220), male $12.4 \mathrm{~mm}$ (NSMT-Cr 24219), female $13.3 \mathrm{~mm}$ (NSMTCr 24221), male, 3 ovig. females, and 2 females (NSMT-Cr 24222), 8 males and 71 females (H. Miyamoto collection); Utoro, Abashiri (base of a cliff, under litter); 1 August 1988; H. Miyamoto coll. Female $12.4 \mathrm{~mm}$ (NSMT-Cr 24217), 2 males, 2 ovig. females, and 3 females (NSMT-Cr 24218), 14 males and 9 females (H. Miyamoto collection); On-neto, Nemuro (forest of a shrine, under litter); 2 August 1988; H. Miyamoto coll. 2 females (NSMT-Cr 24223), 5 males and 24 females (H. Miyamoto collection); Rausu (near entrance of the Nature Park, floor of birch forest); 1 August 1988; H. Miyamoto coll. Male $9.2 \mathrm{~mm}$ (NSMT-Cr 24224), ovig. fe-
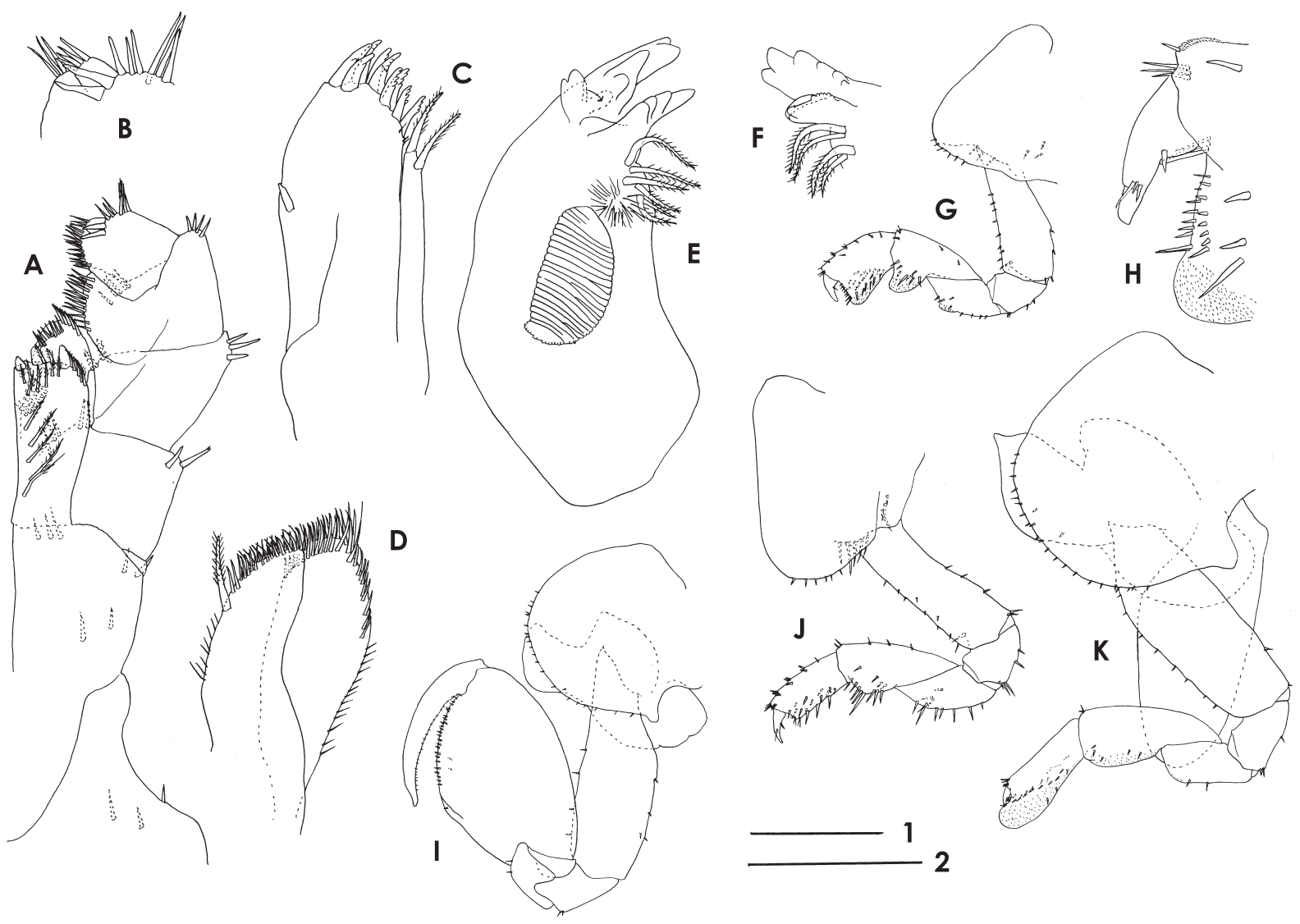

Fig. 2. Ezotinorchestia solifuga (Iwasa, 1939). Male, $12.9 \mathrm{~mm}$ (NSMT-Cr 24220); female, 13.3 mm (NSMT-Cr 24221). Utoro, Abashiri, Hokkaido, Japan. A, maxilliped; B, palp article 4 of maxilliped; C, maxilla 1; D, maxilla 2; E, left mandible; F, distal part of right mandible; G, J, gnathopod 1; H, palmar margin and dactylus of gnathopod 1; I, K, gnathopod 2. J, K, female; others, male. Scale 1, 0.5 mm for G and I, $0.1 \mathrm{~mm}$ for $\mathrm{A}, \mathrm{C}-\mathrm{F}$ and $\mathrm{H}, 0.05 \mathrm{~mm}$ for $\mathrm{B}$; scale $2,1.0 \mathrm{~mm}$ for $\mathrm{J}$ and $\mathrm{K}$. 


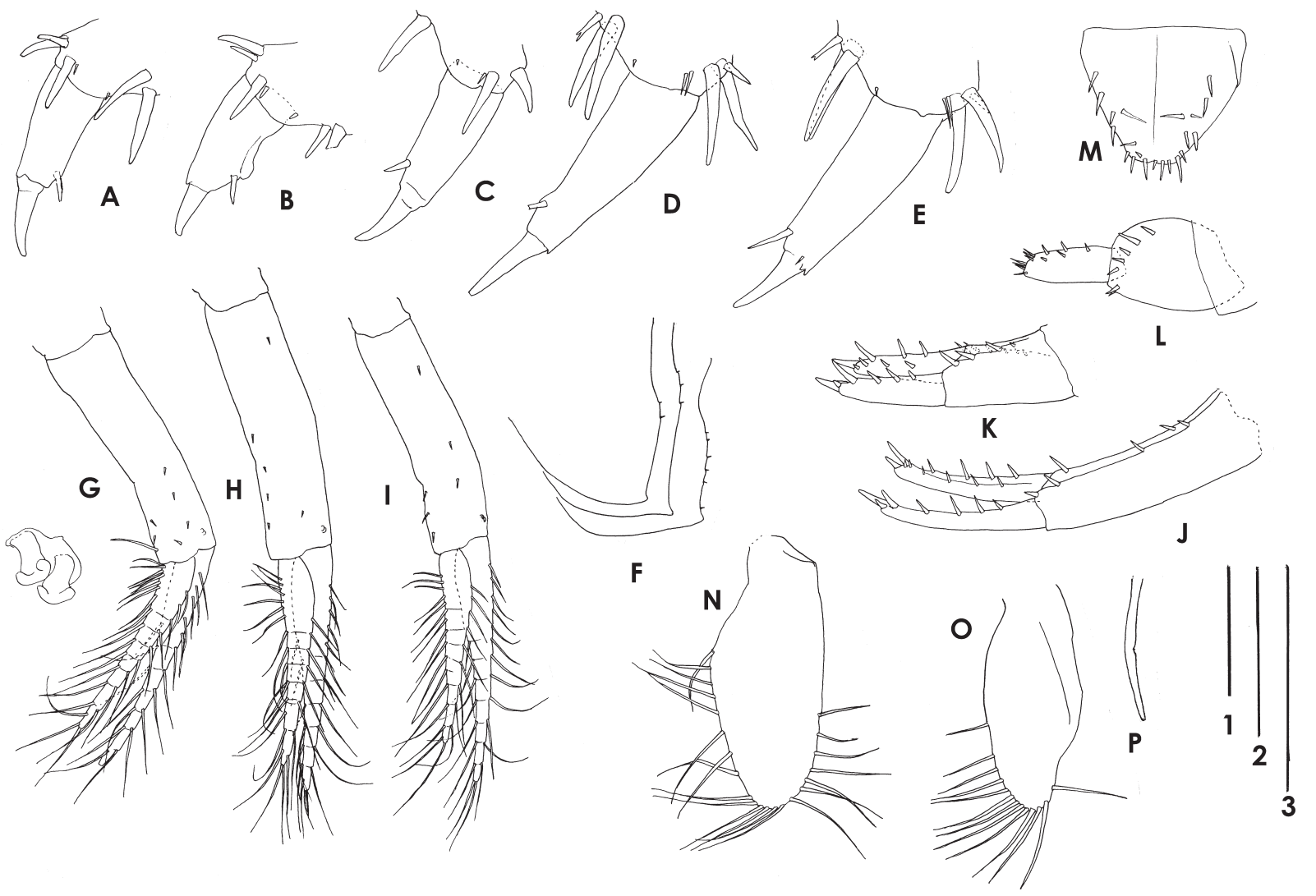

Fig. 3. Ezotinorchestia solifuga (Iwasa, 1939). Male, $12.9 \mathrm{~mm}$ (NSMT-Cr 24220); female, $13.3 \mathrm{~mm}$ (NSMT-Cr 24221). Utoro, Abashiri, Hokkaido, Japan. A-E, distal part of pereopods 3-7; F, pleonite side plates; G-I, pleopods 1-3, with retinacula of pleopod 1; J-L, uropods 1-3; M, telson; N, O, oostegites of pereopods 2, 5; P, tip of seta on oostegite of pereopod 4. N, O, female; others, male. Scale $1,1.0 \mathrm{~mm} \mathrm{for} \mathrm{F,} 0.5 \mathrm{~mm}$ for $\mathrm{L}$ and $\mathrm{M}, 0.1 \mathrm{~mm}$ for $\mathrm{A}-\mathrm{E}$; scale 2, $1.0 \mathrm{~mm}$ for $\mathrm{N}$ and $\mathrm{O}$; scale 3, $1.0 \mathrm{~mm}$ for $\mathrm{G}-\mathrm{K}, 0.1 \mathrm{~mm}$ for P.

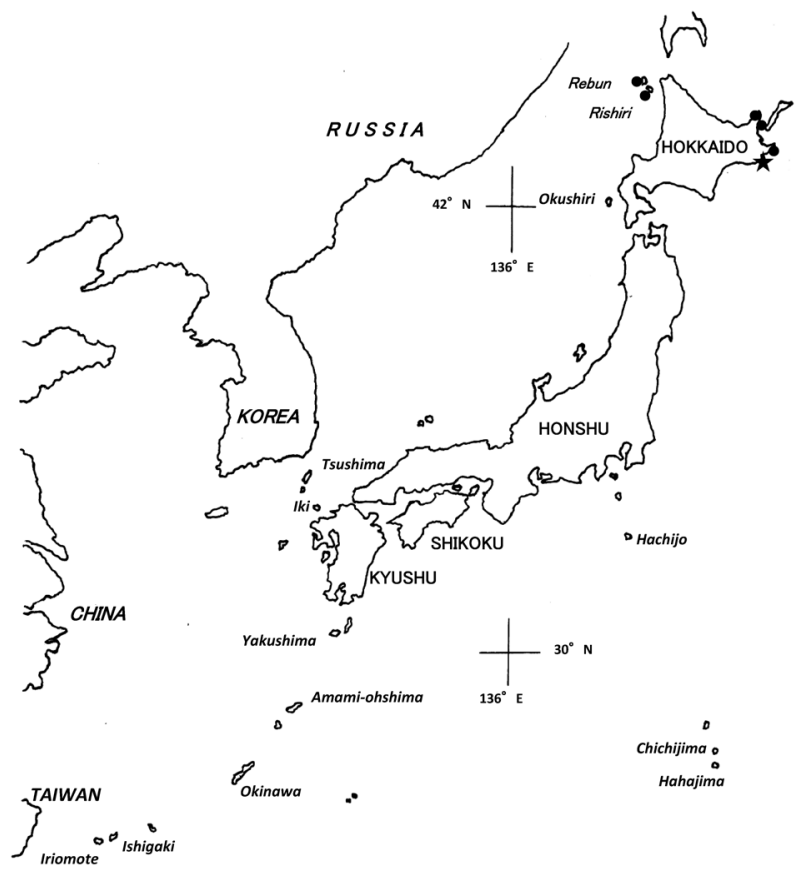

Fig. 4. Geographical distribution of Ezotinorchestia solifuga (Iwasa, 1939). Black circles: sampling sites of E. solifuga in this study. Star: type locality in Iwasa (1939). male $9.2 \mathrm{~mm}$ (NSMT-Cr 24225), ovig. female (NSMT-Cr 24226), 2 males and 2 females (NSMT-Cr 24227); Senhoshi, Rishiri Is. (Picea and Abies forest, $25 \mathrm{~m}$ alt.); 31 July 2007; M. Sato and K. Ishii coll. Male and juvenile (NSMT-Cr 24228); Kafukai, Rebun Is. (Abies forest, $20 \mathrm{~m}$ alt.); 31 May 2007; H. Miyamoto and K. Ishii coll.

Description of male (NSMT-Cr 24220, $12.9 \mathrm{~mm}$ ). Antenna 1 (Fig. 1A, B) with peduncular article 3 distinctly longer than either article 1 or 2; flagellum with 6 articles. Antenna 2 (Fig. 1A), peduncular article 5 subequal to articles 3 and 4 combined in length, flagellum with 19 articles. Mouthparts (Figs 1C, D, 2A-F) as in generic diagnosis. Gnathopod 1 (Fig. 2G) with merus bearing small pellucid lobe, carpus ca. 1.3 times as long as propodus, with prominent pellucid lobe, propodus with submarginal row of 6 robust setae, surface of anterodistal corner scabrous (Fig. 2H). Gnathopod 2 (Fig. 2I) with propodus distally smoothly broadened, palm smooth, as long as posterior margin, dactylus weakly attenuate. Locking robust setae of pereopods 3-7 reduced (Fig. 3A-E). Dactylus of pereopod 4 pinched (Fig. 3B). Bases of pereopods 5-7 (Fig. 1A) shallowly rounded posteriorly. Merus and carpus of pereopod 7 slender, similar to those of pereopod 6.

Pleonite side plates (Fig. 3F) weakly acuminate posteriorly, with several setae on posterior margins. Peduncles of 
pleopods 1-3 (Fig. 3G-I) with facial and marginal robust setae, occasionally with plumose setae; rami developed, with ca. 8 articles, 0.98, 0.96, and 1.06 times as long as respective peduncles. Uropod 1 (Fig. $3 \mathrm{~J}$ ) with peduncle bearing 5 outer, 3 and 1 tiny inner marginal robust setae; outer ramus with 4 marginal robust setae, inner ramus with 4 outer and 4 dorsomarginal robust setae. Uropod 2 (Fig. 3K) with peduncle bearing 4 outer marginal and 6 inner-medial marginal robust setae, outer ramus with 3 marginal robust setae, inner ramus with 3 outer marginal (distalmost one closely set to apical robust setae) and 2 dorsomarginal robust setae. Uropod 3 (Fig. 3L) with peduncle bearing 7 robust setae from dorsal to ventrodistal margin, ramus short, 0.71 times as long as peduncle, with 5 marginal and $c a$. 8 distal setae. Telson (Fig. 3M) with 10-11 robust setae per lobe.

Description of female (NSMT-Cr 24221, $13.3 \mathrm{~mm}$ ). Gnathopod 1 (Fig. 2J) with carpus ca. 1.5 times as long propodus, propodus lacking scabrous surface. Gnathopod 2 (Fig. 2K) with basis almost parallel-sided, merus with small lobe with scabrous surface, propodus with $c a$. 4 submarginal setae. Oostegites of pereopods 2 and 5 respectively with 25 and 13 simple-tipped marginal setae (Fig. 3N, O, P).

Distribution. The present species is terrestrial and was collected from under litter of coastal forests of eastern Hokkaido and islands off northern Hokkaido (Fig. 4). The original description was based on the material from Akkeshi near Kushiro, in Hokkaido (Iwasa 1939).

Remarks. The present material accords well with the original description given by Iwasa (1939), except for the number of robust setae on the telson. Five specimens examined in the present study with body lengths of $9.2-12.9 \mathrm{~mm}$ bear 8-12 robust setae per lobe whereas the material from Akkeshi displays 5-6 robust setae (Iwasa 1939: pl. 14, fig. x). Although the body length of the depicted specimen was not specified by Iwasa (1939), the difference in the number of setae is very likely related to body size, since the variation in the number of the setae among the five specimens grossly parallels their body length. The gnathopod 1 of male in this species exhibits a prominent pellucid lobe on the carpus, and the scabrous surface on anterodistal part of the propodus, both of which could be additional generic diagnoses.

Sidorov and Barabanschikov (2010) described a female of Orchestia solifuga from "subsurface" water of the Samarga River estuary, northern Primorye, Russia, but the depigmented body, diffuse ocelli, elongate mandible, and peculiar robust setae on the posterior margin of the merus-carpus of pereopod 3 of the Russian material strongly suggest they actually had a different species. Proper generic allocation of this specimen requires further examination of the gnathopods of the males. In terrestrial coastal habitats in Hokkaido, Kokuborchestia kokuboi (Uéno, 1929), Ditmorchestia ditmari (Derzhavin, 1923), and Ezotinorchestia solifuga occur. Kokuborchestia kokuboi is found in the southeast (Morino and Miyamoto 2015a) whereas E. solifuga inhabits the northern to eastern coast (Fig. 4). Ditmorchestia ditmari is confined to a small area in the east (Morino and Miyamoto 2015b), possibly representing the southern-most population of this species, which ranges north to Kamchatka.
The reproductive season of the Rishiri population is estimated to be from July to September, and the egg number per female is around 14 (Morino et al. 2009).

\section{Acknowledgments}

We express our hearty thanks to Dr J. K. Lowry and Dr M. J. Grygier for their careful reading of an earlier draft and improvement of the English. Dr K. Ishii kindly put his material at our disposal and we express our deep gratitude to him. Dr H. Komatsu of the National Museum of Nature and Science assisted in the preparation of the manuscript and we are grateful to his help.

\section{References}

Bousfield, E. L. 1982. The amphipod superfamily Talitroidea in the northeastern Pacific region. 1. Family Talitridae: systematics and distributional ecology. National Museums of Canada, Publications in Biological Oceanography 11: i-vii, 1-72.

Bousfield, E. L. 1984. Recent advances in the systematics and biogeography of landhoppers (Amphipoda: Talitridae) of the Indo-Pacific region. Bernice P. Bishop Museum Special Publication 72: 171210.

Bulycheva, A. I. 1957. Morskie Bloxi Morej SSSR i Sopredelnyx Vod (Amphipoda-Talitroidea). Opredeliteli po Faune SSSR [The Sand Fleas of the USSR and Adjoining Waters (Amphipoda-Talitridae). Keys to the Fauna of the USSR]. Zoological Institute, Academy of Science 65, 186 pp. [In Russian]

Iwasa, M. 1939. Japanese Talitridae. Journal of the Faculty of Science, Hokkaido Imperial University, Series 6, Zoology 6: 255-296, pls 9-18.

Lowry, J. K. and Fanini, L. 2013. Substrate dependent talitrid amphipods from fragmented beaches on the north coast of Crete (Crustacea, Amphipods, Talitridae), including a redefinition of the genus Orchestia and descriptions of Orchestia xylino sp. nov. and Cryptorchestia gen. nov. Zootaxa 3709: 201-229.

Miyamoto, H. 1984. [Distribution of land-hoppers (Talitridae, Amphipoda, Crustacea) in Hokuriku District, Japan]. Fukuikenritsu Fujishima Kotogakko Kenkyu Shuroku 23: 1-13. [In Japanese]

Morino, H. 2014. A new land-hopper genus, Mizuhorchestia, from Japan (Crustacea, Amphipoda, Talitridae). Bulletin of the National Museum of Nature and Science, Series A 40: 117-127.

Morino, H. 2015. Amphipoda. In: Aoki, J. (Ed.) Pictorial Keys to Soil Animals of Japan, 2nd ed. Pp. 1069-1089. Tokai University Press, Hadano. [In Japanese]

Morino, H., Ishii, K., Sato, M., and Miyamoto, M. 2009. Terrestrial Talitridae (Crustacea: Amphipoda) from Rishiri and Rebun Islands, northern Hokkaido. Rishiri Research 28: 25-28. [In Japanese]

Morino, H. and Miyamoto, H. 2015a. Description of a new land-hopper genus, Kokuborchestia gen. nov. and redescription of K. kokuboi (Uéno, 1929) com. nov. (Crustacea, Amphipoda, Talitridae). Bulletin of the National Museum of Nature and Science, Series A 41: 155-162.

Morino, H. and Miyamoto, H. 2015b. Description of a new talitrid genus Ditmorchestia with redescription of D. ditmari (Derzhavin, 1923) com. nov. (Crustacea, Amphipoda, Talitridae). Bulletin of the National Museum of Nature and Science, Series A 41: 217224.

Pavesi, L., Wildish, D. J., Gasson, P., Lowe, M., and Ketmaier, V. 2015. 
Further morphological and molecular studies of driftwood hoppers (Crustacea: Amphipoda: Talitridae) from Mediterranean/ north-east Atlantic coastlines. Journal of Natural History 49: 1047-1071.

Sidorov, D. A. and Barabanschikov, E. I. 2010. Findings of stygobiont and amphibiotic Peracarida (Amphipoda) in subsurface waters in the Samarga R. basin (northern Primorye) and some considerations about the taxonomic position of "Orchestia" solifuga Iwasa. Vestnik SVNC DVO RAN 4: 70-75. [In Russian with English summary] 